\title{
Unmet needs of activities of daily living among a community-based sample of disabled elderly people in Eastern China: a cross-sectional study
}

\author{
Shen Chen ${ }^{1}$, Jing Zheng ${ }^{1}$, Chen Chen ${ }^{1}$, Ying Xing ${ }^{1}$, Yan Cuil ${ }^{1 *}$, Y Yaping Ding ${ }^{1}$ and Xiuyun $\mathrm{Li}^{2}$
}

\begin{abstract}
Background: China has the largest population of partially or completely disabled elderly people in the world. Although the disabled elderly people try to remain independent in their lives, many still need assistance from others. Failure to obtain sufficient assistance creates a situation of unmet need. Unmet needs of activities of daily living (ADL) for disabled elderly people pose significant risks for hospitalization and mortality and cause an increased economic burden on families and society. This study aimed to identify the prevalence and risk factors of unmet needs among the disabled elderly in China to guide government toward corrective action.

Methods: A total of 303 older adults from 15 communities in Nanjing, China were recruited. The Barthel Index (BI) and Functional Activities Questionnaire (FAQ) were used to screen disabled elderly people from the communities. These disabled elderly participants were then investigated in terms of their unmet ADL needs, using an unmet needs assessment form, which had been adapted from the BI and FAQ. Additionally, the Zarit Burden Interview and Family Caregiver Task Inventory were used to survey the main caregivers. Finally, univariate analysis was first used to filter out candidate impact factors, and then, binary logistic regression analysis was used to adjust for cofounders and determine reliable risk factors.
\end{abstract}

Results: A total of $93.1 \%$ of the disabled elderly people in our study reported at least one unmet need. The prevalence of unmet needs for different ADL tasks ranged from 4.6 to $77.2 \%$. The unmet needs with the highest percentages were using vehicles (77.2\%), using stairs (73.1\%), working on a hobby (72.1\%), social interaction (62.6\%) and ambulating (60.1\%). The factors influencing unmet needs were related to the degree of disability in instrumental activities of daily living (IADL) $(\mathrm{OR}=1.079, p \leq 0.01)$, the relationship with caregivers $(\mathrm{OR}=1.429, p \leq 0.05)$ and the monthly income of caregivers $(\mathrm{OR}=0.679, \mathrm{p} \leq 0.05)$.

Conclusion: Disabled elderly people living in communities had a high percentage of unmet needs for activities of daily life that required going outside the bedroom and involved spiritual aspects. Unmet needs increased with worsening disability status in IADL, more distanced relationships with caregivers and lower incomes of caregivers. Both government and caregivers should take more action to prevent or reduce unmet needs among the elderly.

Keywords: Unmet needs, Activities of daily living, Aged, Disability, China

\footnotetext{
* Correspondence: cyan@njmu.edu.cn

${ }^{1}$ School of Nursing, Nanjing Medical University, 101 Longmian Avenue,

Jiangning District, Nanjing 211166, People's Republic of China

Full list of author information is available at the end of the article
}

(c) The Author(s). 2018 Open Access This article is distributed under the terms of the Creative Commons Attribution 4.0 International License (http://creativecommons.org/licenses/by/4.0/), which permits unrestricted use, distribution, and reproduction in any medium, provided you give appropriate credit to the original author(s) and the source, provide a link to the Creative Commons license, and indicate if changes were made. The Creative Commons Public Domain Dedication waiver (http://creativecommons.org/publicdomain/zero/1.0/) applies to the data made available in this article, unless otherwise stated. 


\section{Background}

The unprecedented and pervasive process of population aging has become a global challenge that no longer exists only in developed countries [1]. Because of the "One Child Policy" adopted in 1979 as well as economic development and advances in medical technology, China became an "aging society" in approximately the year 2000 [2]. The latest data published by the National Bureau of Statistics of China indicated that more than 143.86 million people were over 65 years old in 2015, approximately $10.47 \%$ of the total population of China [3].

Along with the acceleration of aging, the number of disabled elderly people is also rapidly increasing. The International Classification of Functioning, Disability and Health (ICF) defines disability as an umbrella term for impairments, activity limitations and participation restrictions [4]. Completely disabled persons and partially disabled persons with functional deficits due to age, disease or accidents are all considered disabled in this study. Evaluating basic activities of daily living (BADL) and instrumental activities of daily living (IADL) is considered the most common way to screen for disabilities in the elderly [5]. Statistics investigated by the Research Group of China Research Center on Aging show that by 2010, China had more than 22.15 million partially disabled and 10.84 million completely disabled elderly people (over 60 years old), accounting for 12.75 and $6.25 \%$, respectively, of the total elderly population [6]. Many studies have explained the relationships between aging and disability. One theory is that due to a decline in mortality rates, the onset of disability will be postponed until late in life and thus will be "compressed" for elderly people who live with disability [7]. Studies also suggested that chronic diseases, such as hypertension, diabetes and cerebrovascular disease, common in the elderly, may result in disability [8, 9]. Multimorbidity among the elderly, which is a world-wide public health issue, is significantly associated with disability $[10,11]$.

Disability can cause many adverse consequences, such as a decline in quality of life and physical or mental health and an increased risk of harm from accidents [12, 13]. However, as a developing country with a large disabled aging population, China has an even larger challenge in caring for aging adults: unlike Japan and Germany, China does not have a social nursing insurance system. Thus, the disabled elderly people cannot receive additional insurance money to support their everyday lives. In China, only when the elderly suffer from severe organic diseases will costs be partly payed by medical insurance. Similar to many other developed countries, China has already established a basic medical insurance system, which covers approximately 95\% of the total population [14]. However, not everyone can receive high-quality medical services without worrying about money. China has 3 types of social medical insurance systems [15]. Less than $20 \%$ of the elderly have Basic Medical Insurance for Urban Employees, where they do not have to pay any insurance fees after retirement and can get the highest reimbursement ratio of medical costs. The rest of the elderly either have Basic Medical Insurance for Urban Residents (Freelancers and the unemployed) or New Rural Cooperative Medical Insurance, which requires continued payment of insurance fees, even after retirement, and has more limitations on receiving medical services. In contrast to western countries, the wealthy in China seldom donate money to support the disabled elderly, and subsidies from government are very low. Although the elderly living in some large cities have experienced substantial improvement in disability treatment due to additional resources for caregiving over the past decade, most elderly people still live in a situation without long-term care and specific insurance [16]. Nursing homes in China are still at the preliminary stage with only approximately 6.72 million beds available in the entire country [17]. Hence, most disabled elderly people are cared for by their family members, especially women [18]. However, traditional caregivers experience a much heavier burden than previously, as there are more and more nuclear families (a couple with an unmarried child) and women with careers in China [19].

Although the disabled elderly try to remain independent in BADL/IADL, some may still need assistance from others. Failure to obtain sufficient assistance creates a situation of unmet need [20]. Kim defines unmet need as "the gap between the amount of long-term care need, as assessed by an individual, and the actual resources the individual has at his/her disposal to meet that need" [21]. Unmet needs occur when assistance is not provided or is inadequate [22]. Unmet need is usually measured by self-report, but sometimes, caregivers and care-recipients share their different attitudes toward perceived unmet needs for services [23]. There are studies available that indicate that unmet needs among disabled elderly people lead to adverse consequences, including higher risks of hospitalization, hospital readmission, emergency department admission, psychological distress and death [24-27]. To reduce the lack of individualized care, some countries have established long-term care systems. Japan and Germany are famous for their universal coverage of long-term care systems with services provided by non-profit organizations [28]. These systems are financed through government, employers and employee contributions. The United States also has an excellent system with services provided by for-profit organizations, including adult day service centers, home health agencies, nursing homes and residential care communities [29]. However, for these, the elderly need commercial insurance. 
Most previous studies related to unmet need were conducted in developed countries, but the prevalence of unmet needs varied widely in different countries, regions and races. Compared with other countries, China has large numbers of disabled elderly people and has different cultures, policies and lifestyles, so it is urgent to investigate the problems of unmet need in China, where such types of studies are rare. China may not have an optimistic result regarding unmet needs because the healthcare system in China is still not very efficient. Therefore, the present study aims to identify the prevalence and risk factors of unmet need among the Chinese disabled elderly. The findings may be helpful for government and caregivers to take more useful action to prevent or reduce unmet needs. Thus, disabled elderly people can have the chance to improve or maintain an optimal level of physical functioning and quality of life.

\section{Methods}

The study protocol received approval by the Ethics Committee of Nanjing Medical University with approval no. 2017-579.

\section{Data source and analytic sample}

Data for this study were collected from 15 communities in 7 districts of Nanjing city, Jiangsu Province, which is located in the coastal area of Eastern China. These communities are scattered in urban, suburban and rural areas. Individuals included in this study were selected from the electronic health systems in different communities with an oral agreement to participate in the study. Criteria for inclusion in the study were: age over 60 years old; meeting the disability criteria of the Barthel Index (score $\leq 60)$ or Functional Activities Questionnaire (score $\geq 5$ ); ability to answer questions or have caregivers who are familiar with the situation answer questions. Elderly people with intellectual disabilities were excluded from this study. The sample size for this study was calculated as 291 using the formula: $\mathrm{N}=\mu_{\alpha}{ }^{2} \times \pi(1-\pi) / \delta^{2}$. In this formula, $\mu_{\alpha}=1.96, \delta=0.1 \pi$, and $\pi=56.88 \%$ (according to previous studies [30]). The final sample yielded 303 community-dwelling disabled elderly people who met the criteria.

\section{Instruments}

Several questionnaires were used to measure different variables in this cross-sectional study, including the following:

1. Demographic questionnaire (Additional file 1): We designed this questionnaire ourselves; it was divided into two parts according to care recipient or caregiver. The care recipient section contains age, gender, marital status, education, income, medical expenses, and cause and length of disability of the disabled elderly person. The second section contains age, gender, education, relationship with the care recipient and income of main caregivers.

2. Barthel Index (BI) (Additional file 2): The BI was modified by Mahoney and Barthel in 1965 [31] and is used for measuring the functional status of BADL, which consists of feeding, dressing, bathing, grooming, toileting, bowel control, bladder control, chair/bed transfer, ambulating, and using stairs. Scores range from 0 to 100 to identify the severity of disability in BADL; the higher the score, the lower the level of independence. Scores are classified into 5 groups: $0-19$ is complete dependency, 20-40 is severe dependency, 41-60 is moderate dependency, 61-99 is mild dependency, and 100 is no dependency. Participants can be defined as disabled in BADL when the total score is $\leq 60$.

3. Functional Activities Questionnaire (FAQ) (Additional file 3): The FAQ was modified by Pfeffer in 1982 [32], and is used for measuring the functional status of IADL. It has 10 questions, which can be abbreviated as financial management, assembling affairs, shopping, working on a hobby, doing housework, cooking, learning about current events, communicating, memorizing, and using vehicles. Each item's score ranges from 0 to 3, from independence to dependence. Participants can be defined as disabled in IADL when the total score is $\geq 5$.

4. Zarit Burden Interview (ZBI) (Additional file 4): The ZBI was modified by Zarit in 1980 [33] and is used to measure caregiver burden. The revised version contains 22 items. Each item in the interview is a statement that the caregiver is asked to respond to using a 5-point scale. Response options range from 0 (Never) to 4 (Nearly Always). The higher the total score, the heavier the burden.

5. Family Caregiver Task Inventory (FCTI) (Additional file 5): The FCTI was originally developed by Clark in 1983 [34], was then translated into the Chinese version by Lee from Hong Kong in 2004 [35]; it is used for measuring difficulties in caregiving. The instrument includes 25 items answered on a scale of $0-2$, ranging from no difficulty to difficulty. The higher the total score, the more difficulty in caring for care-recipients.

6. Unmet Needs Assessment (Additional file 6): This tool is a 17-item questionnaire based on perceived need and was adapted from an algorithm created by Allen and Mor in 1997 (see Fig. 1) [36, 37]. Using this tool, unmet need can be filtered according to 3 principles: Are you receiving someone's help? Is the present assistance enough? Were there any negative 


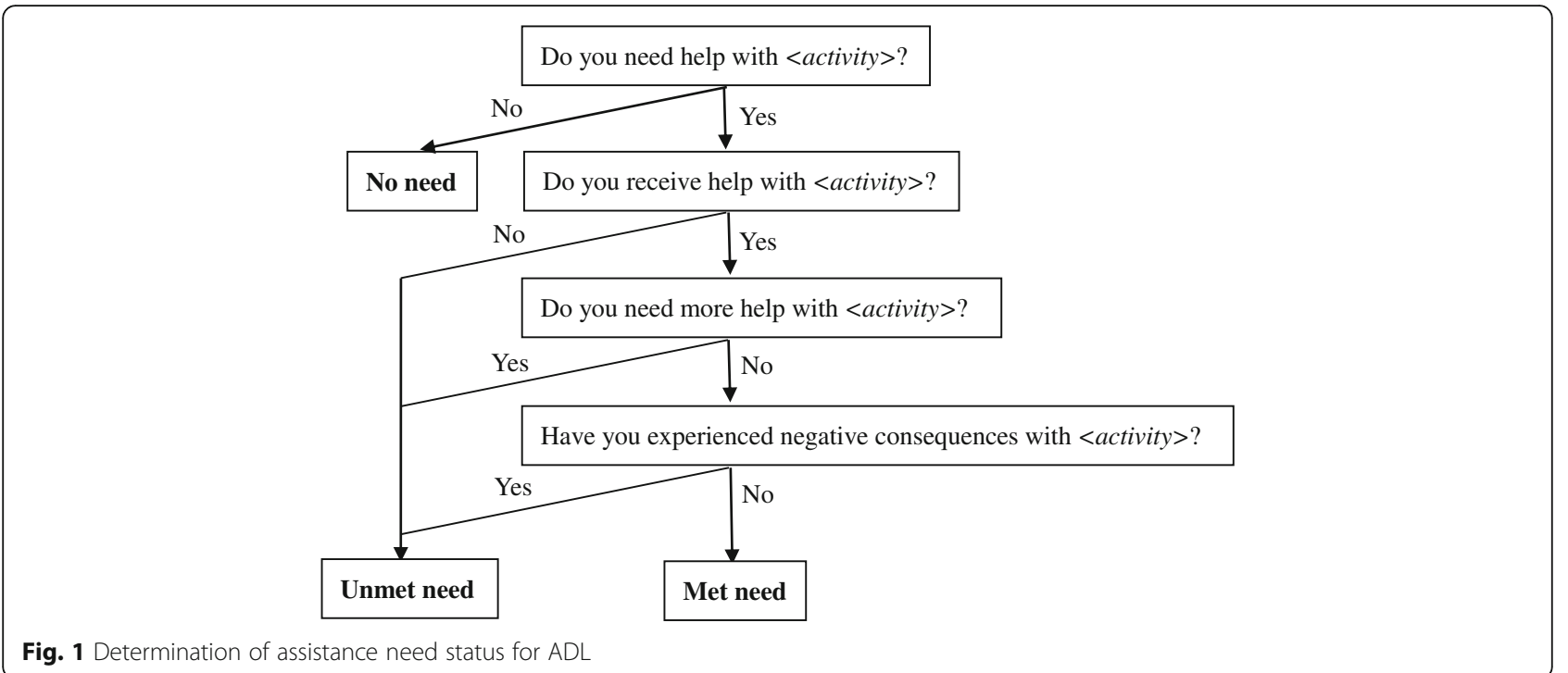

consequences during the past month? Questions used to assess the negative consequences of unmet needs are shown in Table 1. Investigators can conduct interviews with disabled elderly people following the guidelines of this assessment. If respondents did not get help, did not get enough help or experienced any negative consequences in a specific activity, this activity can be considered an unmet need. All items in this questionnaire were picked up from the BI and FAQ with using the bathroom, bowel control and bladder control combined as toileting and learning about current events and communicating summarized as social interaction. The 17 items include feeding, dressing, bathing, grooming, toileting, chair/bed transfer, ambulating, using stairs, financial management, assembling affairs, shopping, working on a hobby, doing housework, cooking, social interaction, memorizing and using vehicles. Of all 17 items, feeding is a special one. If someone cannot eat on their own, he/she should have help from others; otherwise, he/she could die soon and have no chance to participate in this study. Thus, investigators should only identify whether he/she has enough help or negative consequences.

Chinese versions of the BI, FAQ, ZBI and FCTI have been widely used and are all proven to have good reliability and validity in local articles [38].

\section{Procedure}

Fifteen nursing professionals and graduate students underwent a standard training and a 3-day pre-survey prior to commencement of the study to ensure that every investigator was qualified in his/her work. Then, from
December 2016 to July 2017, face-to-face interviews were conducted at participants' homes by at least 2 investigators to ensure the quality of each investigation. BI and FAQ were used first to confirm that selected individuals were in fact disabled. The status of disability can also be measured by these 2 instruments. Afterward, other instruments were used with participants and their caregivers.

\section{Data analysis}

Data analysis was performed using the SPSS 18.0 software package. Frequency was used to describe the disability status and unmet needs of disabled elderly participants and was also used to describe the characteristics of both care recipients and caregivers, together with means and standard deviations. Chi-squared and Wilcoxon tests were employed for qualitative data and non-normally distributed quantitative data, respectively, to examine the association between unmet needs and characteristics. Finally, a binary logistic regression analysis was used to identify significant risk factors for unmet needs, and confounders were also adjusted in this step.

\section{Results}

\section{Characteristics}

As Table 2 shows, the mean age of the respondents was $82.3(\mathrm{SD}=9.5)$ years, and ages ranged from 60 to 109 years. Of the 303 disabled elderly people, slightly more females (54.4\%) participated than males (45.5\%), and the ratio of married to unmarried, which also includes divorced or widowed, was approximately 1:1. Nearly $60 \%$ of the elderly had only primary school-level education or below, 39.9\% received less than 1000 yuan per month (approximately 158.7 USD, April 10, 2018) from their insurance or other source of finances, and their medical expenses were also less than 1000 yuan 
Table 1 Questions used to assess negative consequences of unmet needs for ADL tasks

\begin{tabular}{|c|c|}
\hline Items & Questions (during the past month) \\
\hline Feeding & Were there times you were unable to eat when you were hungry because no one was available to help you have food? \\
\hline Dressing & Did you experience discomfort because you were unable to get assistance to change your dirty or wet clothes as soon as possible? \\
\hline Bathing & $\begin{array}{l}\text { Did you experience discomfort because you were unable to get assistance to bathe as often as possible? } \\
\text { Did you experience a scald caused by bathing with water that was too hot? }\end{array}$ \\
\hline Grooming & Did you experience discomfort with your face/teeth/hair because you were unable to get assistance to groom as often as possible? \\
\hline Toileting & $\begin{array}{l}\text { Were there times you had no choice but to hold back urine for a long time because no one was available to help you go to the } \\
\text { restroom? } \\
\text { Did you wet or soil yourself because you did not have help getting to the restroom? }\end{array}$ \\
\hline Chair/bed transfer & $\begin{array}{l}\text { Were there times you had no choice but to lie on the bed for a long time because no one was available to help you get out of bed? } \\
\text { Have you ever had pressure sores? }\end{array}$ \\
\hline Ambulating & $\begin{array}{l}\text { Were there times you had no choice but to stay in the bedroom for a long time because no one was available to help you walk } \\
\text { outside? }\end{array}$ \\
\hline Using stairs & $\begin{array}{l}\text { Were there times you had no choice but to stay on the same floor for a long time because no one was available to help you go } \\
\text { downstairs? }\end{array}$ \\
\hline $\begin{array}{l}\text { Financial } \\
\text { management }\end{array}$ & Were there times you lost money or overspent because no one was available to help you do financial management? \\
\hline Assembling affairs & Did you experience chaos in everyday life because you were unable to get assistance to assemble affairs? \\
\hline Shopping & Did you experience inconvenience due to a lack of daily supplies because you were unable to get assistance to do shopping? \\
\hline $\begin{array}{l}\text { Working on } \\
\text { a hobby }\end{array}$ & Were there times you felt very bored because no one was available to help you do recreational activities? \\
\hline $\begin{array}{l}\text { Doing } \\
\text { housework }\end{array}$ & Were there times you had no choice but to live in a dirty environment, because no one was available to help you do housework? \\
\hline Cooking & Did you experience discomfort because you often had to eat food that did not meet your taste? \\
\hline $\begin{array}{l}\text { Social } \\
\text { interaction }\end{array}$ & $\begin{array}{l}\text { Were there times you had no choice but to live alone for a long time because no one was available to help you go outside to chat } \\
\text { with others? }\end{array}$ \\
\hline Memorizing & Were there times you forgot to take medicine or misused medicine because no one was available to remind you to take the medicine? \\
\hline Using vehicles & $\begin{array}{l}\text { Were there times you had no choice but to stay home when there was an urgent issue that needed to be dealt with outside because } \\
\text { no one was available to take you to travel some distance? }\end{array}$ \\
\hline
\end{tabular}

per month. Close to $72 \%$ of the individuals suffered from disability because of disease, and $68.7 \%$ had been considered disabled for more than 24 months.

In the group of main caregivers with a mean age of $59.0(\mathrm{SD}=12.7) 66.6 \%$ were female. Most caregivers only had attained primary education. Approximately $32.7 \%$ of caregivers were care workers who received a salary from a disabled elderly person, followed by the children (31.3\%), and spouses $(23.8 \%)$ of disabled elderly people. Monthly, $38.6 \%$ of caregivers earn 1000-3000 yuan, followed by 3001-5000 yuan (24.4\%) and less than 1000 yuan (23.4\%).

\section{Disability status of the elderly and caring burden and difficulties of caregivers}

As Table 3 shows, the mean BI score was $40.4(\mathrm{SD}=32.1$ ); thus, respondents in this study were moderately dependent in BADL overall. There were 3 participants with no dependency in BADL; however, they were still classified as disabled people because they were blind people who could serve themselves in BADL but had difficulty dealing with IADLs, which are more complicated.
Respondents with complete dependency occupied the highest percentage (33.3\%), followed by mild dependency (31.0\%) in BADL. The mean FAQ score, which can indicate disability in IADL, was $21.1(\mathrm{SD}=8.1)$. The mean FCTI score, which can indirectly reveal the ability to care for the disabled person, was $11.2(\mathrm{SD}=7.6)$. The mean ZBI score showed that overall, the main caregivers had a moderate burden in caring for a disabled elderly person.

\section{Prevalence of needed help and unmet need in ADL tasks}

A total of 282 respondents reported at least one unmet need, $93.1 \%$ of all the samples. As Table 4 shows, the prevalence ranged from $58.4 \%$ (grooming) to $98.3 \%$ (shopping and using vehicles) depending on the type of help needed. More than $90 \%$ of respondents needed assistance in 6 activities of daily life. These items were shopping, using vehicles, using stairs, assembling affairs, cooking and ambulating. The prevalence of unmet need ranged from $4.6 \%$ (financial management) to $77.2 \%$ (using vehicles). Five items had a greater than 50\% prevalence of unmet need: using vehicles, using stairs, working on a hobby, social interaction and ambulating. 
Table 2 Demographic characteristics of disabled elderly participants and their main caregivers $(N=303)$

\begin{tabular}{|c|c|c|}
\hline Variables & $\mathrm{n}$ & $\%$ \\
\hline \multicolumn{3}{|l|}{ Disabled elderly people } \\
\hline \multicolumn{3}{|l|}{ Age(year) } \\
\hline Mean(SD) & $82.3(9.5)$ & \\
\hline \multicolumn{3}{|l|}{ Gender } \\
\hline Male & 138 & 45.5 \\
\hline Female & 165 & 54.5 \\
\hline \multicolumn{3}{|l|}{ Marital status } \\
\hline Unmarried & 150 & 49.5 \\
\hline Married & 153 & 50.5 \\
\hline \multicolumn{3}{|l|}{ Living area } \\
\hline Urban & 150 & 49.5 \\
\hline Suburban & 121 & 39.9 \\
\hline Rural & 32 & 10.6 \\
\hline \multicolumn{3}{|l|}{ Education } \\
\hline Illiterate & 115 & 38.0 \\
\hline Primary school & 69 & 22.8 \\
\hline Junior high school & 38 & 12.5 \\
\hline Senior high school & 40 & 13.2 \\
\hline College and above & 41 & 13.5 \\
\hline \multicolumn{3}{|l|}{ Income (month) } \\
\hline$\leq 1000$ yuan & 121 & 39.9 \\
\hline $1001-3000$ yuan & 51 & 16.8 \\
\hline $3001-5000$ yuan & 69 & 22.8 \\
\hline$>5000$ yuan & 62 & 20.5 \\
\hline
\end{tabular}

Medical expense (month)

$$
\begin{aligned}
& \leq 1000 \text { yuan } \\
& 1001-3000 \text { yuan } \\
& 3001-5000 \text { yuan } \\
& >5000 \text { yuan }
\end{aligned}
$$

Cause of disability

Diseases

Accidents

Caducity

Length of disability

$$
\begin{aligned}
& \leq 12 \text { months } \\
& 13-24 \text { months }
\end{aligned}
$$$$
>24 \text { months }
$$

Main caregivers

Age (year)

Mean(SD)

Gender

Male

Female

\begin{tabular}{|c|c|c|}
\hline Variables & $n$ & $\%$ \\
\hline \multicolumn{3}{|l|}{ Education } \\
\hline Primary school & 166 & 54.8 \\
\hline Junior high school & 86 & 28.3 \\
\hline Senior high school & 35 & 11.6 \\
\hline College and above & 16 & 5.3 \\
\hline \multicolumn{3}{|l|}{ Relationship } \\
\hline Spouse & 72 & 23.8 \\
\hline Children & 95 & 31.3 \\
\hline Children-in-law & 18 & 5.9 \\
\hline Other relatives & 13 & 4.3 \\
\hline Care workers & 99 & 32.7 \\
\hline Social worker & 6 & 2.0 \\
\hline \multicolumn{3}{|l|}{ Income (month) } \\
\hline$\leq 1000$ yuan & 71 & 23.4 \\
\hline $1001-3000$ yuan & 117 & 38.6 \\
\hline $3001-5000$ yuan & 74 & 24.4 \\
\hline$>5000$ yuan & 41 & 13.5 \\
\hline
\end{tabular}

Table 2 Demographic characteristics of disabled elderly participants and their main caregivers $(N=303)$ (Continued)

Risk of unmet needs by demographic characteristic of disabled elderly people and caregivers

The mean quantity of unmet needs was $4.98(\mathrm{SD}=3.17)$, which ranged from 0 to 16 with a median of 5 . Therefore, all respondents can be divided into two groups. One group's number of unmet needs was no more than 5 , and the other's number of unmet needs was no less than 6. These 2 groups can also be understood in

Table 3 Disability status, caring burden and difficulties ( $N=303)$

\begin{tabular}{lll}
\hline Variables & $\mathrm{N}$ & $\%$ \\
\hline BI & & \\
Mean(SD) & $40.4(32.1)$ & \\
No dependency (100 points) & 3 & 1.0 \\
Mild dependency (61-99 points) & 94 & 31.0 \\
Moderate dependency (41-60 points) & 49 & 16.2 \\
Severe dependency (20-40 points) & 56 & 18.5 \\
Complete dependency (0-19 points) & 101 & 33.3 \\
FAQ & & \\
Mean(SD) & $21.1(8.1)$ & \\
ZBI & & \\
Mean(SD) & $27.7(15.0)$ & \\
FCTI & & \\
Mean(SD) & $11.2(7.6)$ & \\
\hline
\end{tabular}

66.7 BI Barthel Index, FAQ Functional Activities Questionnaire, ZBI Zarit Burden Interview, FCTI Family Caregiver Task Inventory 
Table 4 Prevalence of needed help and unmet need in ADL tasks $(N=303)$

\begin{tabular}{lllll}
\hline Items & $\begin{array}{l}\text { Needed } \\
\text { help } \\
\left(\mathrm{n}_{1}\right)\end{array}$ & $\begin{array}{l}\text { Rate of needed } \\
\text { help }(\%)\end{array}$ & $\begin{array}{l}\text { Unmet } \\
\text { need } \\
\left(\mathrm{n}_{2}\right)\end{array}$ & $\begin{array}{l}\text { Rate of unmet } \\
\text { need (\%) }\end{array}$ \\
\hline Feeding & 218 & 71.9 & 46 & 21.1 \\
Dressing & 212 & 70.0 & 24 & 11.3 \\
Bathing & 234 & 77.2 & 83 & 35.5 \\
Grooming & 177 & 58.4 & 34 & 19.2 \\
Toileting & 222 & 73.3 & 90 & 40.5 \\
Chair/bed transfer & 271 & 89.4 & 125 & 46.1 \\
Ambulating & 283 & 93.4 & 170 & 60.1 \\
Using stairs & 294 & 97.0 & 215 & 73.1 \\
Financial & 238 & 78.5 & 11 & 4.6 \\
management & & & & \\
Assembling affairs & 293 & 96.7 & 26 & 8.9 \\
Shopping & 298 & 98.3 & 54 & 18.1 \\
Working on a hobby & 219 & 72.3 & 158 & 72.1 \\
Doing housework & 245 & 80.9 & 42 & 17.1 \\
Cooking & 289 & 95.4 & 33 & 11.4 \\
Social interaction & 235 & 77.6 & 147 & 62.6 \\
Memorizing & 207 & 68.3 & 24 & 11.6 \\
Using vehicles & 298 & 98.3 & 230 & 77.2 \\
\hline Prevalence of need & & 42.3 & \\
\hline
\end{tabular}

Prevalence of needed help $=n_{1} / 303$; Prevalence of unmet need $=n_{2} / n_{1}$

another way: a group with less unmet needs and a group with more unmet needs. A comparison was carried out that used the 2 groups as dependent variables and characteristics, disability status, caring burden and difficulties as independent variables. As shown in Table 5, Wilcoxon test results revealed a significant association between the scores of BI, FAQ, ZBI, FCTI and unmet needs $(Z=-5.330,-6.342,-3.073,-3.131, p \leq 0.01)$. It was more likely for the elderly people who had worse status in BADL or IADL and whose caregivers had heavier burdens or more difficulty in caring for them to report more unmet needs. The results from the Chi-squared test indicated that medical expenses of disabled elderly people, education, relationships with care-recipients, and income of caregivers were significantly associated with unmet needs $\left(x^{2}=17.979,8.486\right.$, $19.705,13.838, p \leq 0.05, \mathrm{p} \leq 0.01)$, whereas individuals who spent more on medical expenses and those whose caregivers had lower education, a more distanced relationship or lower income were more likely to report more unmet needs.

\section{Predictors of unmet needs-Results of binary logistic regression}

A binary logistic regression that used the 2 groups as the dependent variables and significant risk factors in the univariate analysis as independent variables was used to identify factors associated with unmet needs among disabled elderly people. The regression model was adjusted for all other variables listed in Table 5. Table 6 shows that the likelihood of unmet needs increased with worsening disability status in IADL $(\mathrm{OR}=1.079, p \leq 0.01)$, more distanced relationships with main caregivers (OR $=1.429, p \leq 0.05)$ and lower incomes of main caregivers $(\mathrm{OR}=0.679, \mathrm{p} \leq 0.05)$.

\section{Discussion}

In this study, we found that most disabled elderly people had remained in a situation of low education and low income, which was consistent with several previous studies in China $[13,39,40]$. It was also found that a large percentage of disabled elderly people had suffered from disability for more than 2 years. Hence, it is necessary for China to establish its own long-term care system.

Concordant with a research study in Taiwan [41], middle-aged women were mainly responsible for taking care of the disabled elderly people. This group of caregivers was in a stage of physical deterioration [42], so activities such as moving the elderly person had the potential for injury to the caregiver. Although relatives, especially spouses and children, are still the main caregivers in this study, with the development of the economy, more and more Chinese families have the ability to hire a 24-h care worker to live in their home. However, people with high education refuse jobs as care workers, resulting in a limited number of educated caregivers to improve the quality of life of the disabled elderly person.

The 31.0\% prevalence of elderly people with mild dependency in BADL in our study was much lower compared with a national research study in 2010 [6]. In that national study, the prevalence of disabled elderly people with mild dependency was $84.3 \%$, but the instrument used was the Katz Index, which is much simpler than the Barthel Index. The BI has more levels, so the mild dependency in BI may not be equal to that in Katz. Nevertheless, it is interesting that the mildest and most severe levels of dependency occupied the highest or second highest percentage, respectively, and moderate dependency had only a low percentage in both studies. This result may indicate that mild dependency can easily progress to severe or complete dependency without timely intervention. Thus, it is important to give early care and attention to mildly dependent elderly people to slow the progression to complete dependency.

The results of this study showed that $93.1 \%$ of disabled elderly people had at least one unmet need. This prevalence was much higher than that shown in previous studies carried out in other regions of the world. Desai found that $20.7 \%$ of older Americans had one or more unmet needs in BADL [43]. Rice gave the conclusion that $43.6 \%$ of disabled elderly people in 6 states of the 
Table 5 Risk of unmet needs by demographic characteristic $\left[N=303, M\left(Q_{U}, Q_{L}\right), n(\%)\right]$

\begin{tabular}{|c|c|c|c|c|}
\hline Variables & & Quantity of unmet needs $\leq 5$ & Quantity of unmet needs $\geq 6$ & $z / x^{2}$ \\
\hline \multicolumn{5}{|l|}{ Disabled elderly people } \\
\hline \multicolumn{2}{|l|}{$\left.B\right|^{\mathrm{a}}$} & $57.5(15.0,80.0)$ & $25.0(0.0,55.0)$ & $-5.330^{* *}$ \\
\hline \multicolumn{2}{|l|}{$\mathrm{FAQ}^{\mathrm{a}}$} & $17.5(11.0,26.0)$ & $26.0(20.0,30.0)$ & $-6.342^{* *}$ \\
\hline \multicolumn{2}{|l|}{ Age $\left(\right.$ year) ${ }^{a}$} & $83.0(76.0,88.0)$ & $85.0(79.0,90.0)$ & -1.835 \\
\hline \multirow[t]{2}{*}{ Gender } & Male & $77(47.5)$ & $61(43.3)$ & 0.554 \\
\hline & Female & $85(52.5)$ & $80(56.7)$ & \\
\hline \multirow[t]{2}{*}{ Marital status } & Unmarried & $74(45.7)$ & $76(53.9)$ & 2.039 \\
\hline & Married & $88(54.3)$ & $65(46.1)$ & \\
\hline \multirow[t]{3}{*}{ Living area } & Urban & $77(47.5)$ & 73(51.8) & 5.845 \\
\hline & Suburban & $73(45.1)$ & $48(34.0)$ & \\
\hline & Rural & $12(7.4)$ & 20(14.2) & \\
\hline \multirow[t]{5}{*}{ Education } & Illiterate & $61(37.7)$ & 54(38.3) & 1.191 \\
\hline & Primary school & $39(24.1)$ & $30(21.3)$ & \\
\hline & Junior high school & 21(13.0) & 17(12.1) & \\
\hline & Senior high school & $22(13.6)$ & 18(12.8) & \\
\hline & College and above & 19(11.7) & 22(15.6) & \\
\hline \multirow[t]{4}{*}{ Income (month) } & $\leq 1000$ yuan & 63(38.9) & $58(41.1)$ & 0.762 \\
\hline & 1001-3000 yuan & 29(17.9) & 22(15.6) & \\
\hline & $3001-5000$ yuan & $35(21.6)$ & $34(24.1)$ & \\
\hline & $>5000$ yuan & $35(21.6)$ & 27(19.1) & \\
\hline \multirow[t]{4}{*}{ Medical expense (month) } & $\leq 1000$ yuan & 103(63.6) & $74(52.5)$ & $17.979^{* *}$ \\
\hline & 1001-3000 yuan & $28(17.3)$ & $11(7.8)$ & \\
\hline & $3001-5000$ yuan & $12(7.4)$ & 22(15.6) & \\
\hline & $>5000$ yuan & 19(11.7) & $34(24.1)$ & \\
\hline \multirow[t]{3}{*}{ Cause of disability } & Diseases & 115(71.0) & 103(73.0) & 2.406 \\
\hline & Accidents & $25(15.4)$ & $14(9.9)$ & \\
\hline & Caducity & 22(13.6) & 24(17.0) & \\
\hline \multirow[t]{3}{*}{ Length of disability } & $\leq 12$ month & 18(11.1) & 16(11.3) & 0.159 \\
\hline & 13-24 month & $34(21.0)$ & 27(19.1) & \\
\hline & $>24$ month & 110(67.9) & $98(69.5)$ & \\
\hline \multicolumn{5}{|l|}{ Main caregivers } \\
\hline \multicolumn{2}{|l|}{$\left.\mathrm{ZB|}\right|^{\mathrm{a}}$} & $23.5(13.8,36.0)$ & $30.0(18.0,41.5)$ & $-3.073^{* *}$ \\
\hline \multicolumn{2}{|l|}{$\mathrm{FCTI}^{\mathrm{a}}$} & $8.0(4.0,14.0)$ & $10.0(7.0,16.5)$ & $-3.131^{* *}$ \\
\hline \multicolumn{2}{|l|}{ Age $(\text { year })^{a}$} & $60.0(50.0,70.0)$ & $55.0(55.0,66.0)$ & -1.412 \\
\hline \multirow[t]{2}{*}{ Gender } & Male & $50(30.9)$ & $51(36.2)$ & 0.955 \\
\hline & Female & 112(69.1) & $90(63.8)$ & \\
\hline \multirow[t]{4}{*}{ Education } & Primary school & $83(51.2)$ & $83(58.9)$ & $8.486^{*}$ \\
\hline & Junior high school & $45(27.8)$ & $41(29.1)$ & \\
\hline & Senior high school & 20(12.3) & 15(10.6) & \\
\hline & College and above & 14(8.6) & $2(1.4)$ & \\
\hline \multirow[t]{3}{*}{ Relationship } & Spouse & $52(32.1)$ & $20(14.2)$ & $19.705^{* * b}$ \\
\hline & Children & $54(33.3)$ & $41(29.1)$ & \\
\hline & Children in law & $8(4.9)$ & $10(7.1)$ & \\
\hline
\end{tabular}


Table 5 Risk of unmet needs by demographic characteristic $\left[N=303, M\left(Q_{U}, Q_{L}\right), n(\%)\right]$ (Continued)

\begin{tabular}{llll}
\hline Variables & & Quantity of unmet needs $\leq 5$ & Quantity of unmet needs $\geq 6 \quad 3(6.4)$ \\
\hline & Other relatives & $4(2.5)$ & $58(41.1)$ \\
& Care workers & $41(25.3)$ & $3(2.1)$ \\
& Social worker & $3(1.9)$ & $33(23.4)$ \\
Income (month) & $\leq 1000$ yuan & $38(23.5)$ & $68(48.2)$ \\
& $1001-3000$ yuan & $49(30.2)$ & $23(16.3)$ \\
& $3001-5000$ yuan & $51(31.5)$ & $17(12.1)$ \\
\hline
\end{tabular}

$B$ B Barthel Index, FAQ Functional Activities Questionnaire, ZBI Zarit Burden Interview, FCTI Family Caregiver Task Inventory

${ }^{*} p \leq 0.05 ;{ }^{* *} p \leq 0.01$

a Do not fit the normal distribution

${ }^{\mathrm{b}}$ Use adjusted Chi-squared analysis

United States had unmet needs for assistance [44]. Marc reported that $47.8 \%$ of older American Indians had unmet assistance needs [45]. Regarding some Asian regions, the percentage of disabled adults with unmet needs in Taiwan was $44.8 \%$ [41], and $18.0 \%$ of functionally disabled older Malaysians suffered from unmet needs [46]. Three reasons may explain the huge gap between our study and others in terms of the prevalence of unmet needs. The first is that activities with negative consequences were considered unmet needs in our study. The second is that samples recruited in our research were selected from community electronic health systems, which are more likely to include individuals with special requests. The third is that lifestyles and attitudes of the Chinese may make it possible to have more unmet needs.

The prevalence of unmet needs varied widely in different ADL tasks. Five tasks, using vehicles, using stairs, working on a hobby, social interaction and ambulating,

Table 6 Predictors of unmet needs - results of binary logistic regression ( $N=303)$

\begin{tabular}{lllllll}
\hline Variables & B & S.E. & $\begin{array}{l}\text { Adjusted } \\
\text { OR }\end{array}$ & \multicolumn{2}{c}{ 95\% C.I. for OR } \\
\cline { 6 - 7 } & & & & Lower & Upper \\
\hline Disabled elderly people & & & & & \\
Bl & -0.003 & 0.007 & 0.997 & 0.984 & 1.010 \\
FAQ & 0.076 & 0.026 & $1.079^{* *}$ & 1.025 & 1.136 \\
Medical expense & 0.350 & 0.194 & 1.419 & 0.970 & 2.078 \\
Main caregivers & & & & & \\
ZBI & 0.005 & 0.012 & 1.005 & 0.981 & 1.030 \\
FCTI & 0.034 & 0.024 & 1.035 & 0.987 & 1.085 \\
Education & 0.182 & 0.197 & 1.200 & 0.815 & 1.765 \\
Relationship & 0.357 & 0.144 & $1.429^{*}$ & 1.078 & 1.895 \\
Income & -0.387 & 0.182 & $0.679^{*}$ & 0.475 & 0.970 \\
\hline
\end{tabular}

All the other variables listed in Table 5 were adjusted, but only significant risk factors in the univariate analysis are listed in this table

$B I$ Barthel Index, FAQ Functional Activities Questionnaire, ZBI Zarit Burden Interview, $F C T I$ Family Caregiver Task Inventory

${ }^{*} p \leq 0.05 ;{ }^{* *} p \leq 0.01$ had a rate that was higher than $50 \%$. Hence, a high percentage of disabled elderly people living in communities had unmet needs for activities that required going outside the bedroom and involved spiritual aspects. In the United States, only $11 \%$ of disabled elderly people have unmet needs in activities relating to "getting outside" [43], because a single house and cars are common and affordable for most Americans. However, most Chinese elderly people live in apartments located in buildings with several floors, some of which do not have an elevator. Caregivers who are not educated in the care of the disabled may find it hard to assist with activities such as the use of stairs or vehicles without necessary assistive equipment. However, compared with Western countries, equipment that can lift and move patients is still not very popular in China. Many disabled elderly people have no choice but to stay in their rooms or even lie in bed for long periods of time. The lack of outdoor activities may lead to negative effects in these individuals. Feng found that in rural areas of China, 29.3\% of the disabled elderly people experienced psychological distress [13]. Quail also reported that unmet IADL needs were significantly associated with elevated psychological distress [20]. However, many Chinese caregivers only considered caring for disabled elderly people as satisfying their physical needs. Spiritual activities such as working on a hobby and social interaction were easily ignored. Therefore, it is urgent for caregivers to change their attitudes and for community institutions to give more professional training to caregivers. Disabled elderly people usually have a feeling of inferiority. They are not confident in communicating with others. Thus, encouragement from their caregivers is necessary. In addition, the construction of facilities for recreation and social interaction in Chinese communities is lagging behind other nations, and the provided facilities are usually not suitable for disabled persons. Therefore, community institutions in China still have considerable room for improvement.

Binary logistic regression findings revealed that disability statuses of IADL, relationships with caregivers and caregiver income were significantly associated with 
having more unmet needs. Newcomer and Desal shared the same conclusion; unmet needs increased with increases in the number of BADL limitations among disabled elderly Americans [43, 47]. BADL score was also found to be one of the factors that affected unmet needs in Taiwan [41]. Our results did not find an association between unmet needs and BADL scores after adjusting the binary logistic regression but showed that the disabled elderly people who performed worse in IADL were more likely to have more unmet needs. The different results may also be due to the attitudes of Chinese caregivers, which were mentioned above. Caregivers may ignore the importance of IADL needs. Relationships between disabled elderly people and their caregivers were sorted as 1-6 from the closest (spouse) to the most distanced (social workers) in our study. The closer the relationship, the lower the chance of increased unmet needs. It is easy to assume that caregivers with closer relationships to care-recipients would be more attentive and patient in providing better care. Tennstedt did not find an association between income and unmet needs. In contrast, Desai and Drennan reported significant associations $[43,48,49]$. However, only the caregivers' income was associated with more unmet needs in our study. This association is partly because the satisfaction of caregivers is dependent on money. Additionally, as one of the important parts of caregiving, care workers may do better if they can get a higher salary from care recipients.

Our study has several limitations. The first concerns the cross-sectional design of the study, which could limit its ability to capture the causal relationship among variables. The second comes from the fact that all data were collected through self-reported methods, which may cause information bias. The third is that our samples were recruited only from one region of China, which may cause selection bias. Our future studies will try to collect more samples from different regions, find a better way to improve the precision and multiplicity of analyses and find interventions to decrease the unmet needs of the disabled elderly people.

\section{Conclusions}

In this study, unmet needs for ADL tasks among disabled elderly people are observed to be serious. Disabled elderly people living in communities had a high percentage of unmet needs for activities that require going outside the bedroom and that involve spiritual aspects. Unmet needs increased with worsened disability status in IADL, more distanced relationships with caregivers and lower incomes of caregivers. Government and caregivers should take more useful actions to prevent or reduce unmet needs.

\section{Additional files}

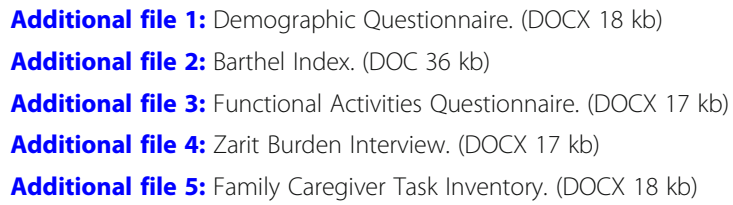

\section{Abbreviations}

95\%Cl: 95\% confidence intervals; ADL: Activities of daily living; BADL: Basic activities of daily ling; BI: Barthel index; FAQ: Functional activities questionnaire; FCTI: Family caregiver task inventory; IADL: Instrumental activities of daily ling; OR: Odds radios; SD: Standard deviation; SE: Standard error; ZBI: Zarit burden interview

\section{Acknowledgements}

We gratefully acknowledge the nursing teachers and graduate students of Nanjing Medical University, staff of 15 community health centers in Nanjing, for their kind assistance in data collection.

\section{Funding}

This study was supported by Scientific Research Innovation Project of Jiangsu Province (No. KYLX16_1085) and Core Subject Construction Fund of Jiangsu Province (No.2014-98). The sponsors had no role in the design and conduct of the study.

\section{Availability of data and materials}

Our data may not be shared directly, because it is our team work, informed consent should be attained from all the team members. Our data or material may be available after contacting corresponding author or first author.

\section{Authors' contributions}

All authors took part in the entire study and approved final manuscript. SC, $Y C, Y D$ contributed to the study design. YC, YD, $X L$ were responsible for establishing connection with communities. SC, JZ, CC, YX, XL contributed to lead the data collection. SC, JZ managed the data. SC performed the data analysis. SC, YC drafted the manuscript. JZ, CC, YX, YD, XL checked the paper.

Ethics approval and consent to participate

Ethics approval of this study was obtained from the Ethics Committee of Nanjing Medical University. Approval number is No.2017-579. Written informed consents were obtained from all the community health centers and oral agreements were received from all the participants prior to study entry. The reason why written consent was not obtained is that many participants did not have enough physical ability or education level to sigh their name. This procedure was also approved by ethics committee.

Consent for publication

Not applicable.

Competing interests

The authors declare that they have no competing interests.

\section{Publisher's Note}

Springer Nature remains neutral with regard to jurisdictional claims in published maps and institutional affiliations.

\section{Author details}

${ }^{1}$ School of Nursing, Nanjing Medical University, 101 Longmian Avenue, Jiangning District, Nanjing 211166, People's Republic of China. ${ }^{2}$ Nanjing Health Service Center of Mofan West Road, No.3 Dinghuaimen, Nanjing 210013, China. 
Received: 5 January 2018 Accepted: 2 July 2018

Published online: 11 July 2018

\section{References}

1. Kinsella K, He W. An ageing world: 2008, US Census Bureau, International population reports, PS95/09-1. Washington DC: US Government Printing Office; 2009.

2. Chen S. Aging with Chinese characteristics: a public policy perspective. Ageing International. 2009;34:172-88.

3. National Bureau of Statistics of People's Republic of China. National economic and social development statistics bulletin, People's Republic of China in 2015. Beijing: National Bureau of Statistics of People's Republic of China. p. 2016. http://data.stats.gov.cn/easyquery.htm?cn=C01\&zb= A0306\&sj=2015

4. World Health Organization. Disability and health. Geneva: World Health Organization; 2016. http://www.who.int/mediacentre/factsheets/fs352/en/

5. Barberger-Gateau P, Rainville C, Letenneur L, Dartigues JF. A hierarchical model of domains of disablement in the elderly: a longitudinal approach. Disabil Rehabil. 2000;22(7):308-17.

6. The Research Group of China Research Center on Aging. Research on situation of urban and rural disabled elderly. Disabil Res. 2011;1:11-6.

7. Fries JF. Aging, natural death, and the compression of morbidity. N Engl J Med. 1980;303:130-5.

8. Uddin MJ, Alam N, Sarma H, Chowdhury MA, Alam DS, Niessen L. Consequences of hypertension and chronic obstructive pulmonary disease, healthcare-seeking behaviors of patients, and responses of the health system: a population-based cross-sectional study in Bangladesh. BMC Public Health. 2014;14(1):547.

9. Dunlop DD, Manheim LM, Sohn MW, Liu X, Chang RW. Incidence of functional limitation in older adults: the impact of gender, race, and chronic conditions. Arch Phys Med Rehabil. 2002;83(7):964-71.

10. Su P, Ding HS, Zhang W, Duan GF, Yang YT, Chen R, et al. The association of multimorbidity and disability in a community-based sample of elderly aged 80 or older in Shanghai, China. BMC Geriatr. 2016;16:178.

11. Wang $X X$, Lin WQ, Chen $X J$, Lin $Y Y$, Huang LL, Zhang SC, et al. Multimorbidity associated with functional independence among community-dwelling older people: a cross-sectional study in southern China. Health Qual Life Outcome. 2017;15:73.

12. Yang $M$, Ding $X$, Dong $B$. The measurement of disability in the elderly: a systematic review of self-reported questionnaires. J Am Med Dir Assoc. 2014;15(2):150

13. Feng $D$, Ji L, Xu L. Mediating effect of social support on the association between functional disability and psychological distress in older adults in rural China: does age make a difference. PLoS One. 2014;9(6):e100945.

14. People's Daily. Basic medical insurance coverage exceeds 1.3 billion. Beijing: People's Daily; 2017. https://www.cn-healthcare.com/article/20171005/ content-496150.html

15. Nanjing Municipal Human Resources and Social Security Bureau. Basic medical insurance of Nanjing. Nanjing: Nanjing Municipal Human Resources and Social Security Bureau; 2017. http://www.njhrss.gov.cn

16. Feng Q, Zhen Z, Gu D, Wu B, Duncan PW, Purser JL. Trends in ADL and IADL disability in community-dwelling older adults in shanghai, China, 1998-2008. J Gerontol B Psychol Sci Soc Sci. 2013;68(3):476-85.

17. Ministry of Civil Affairs of the People's Republic of China. Social services development statistical communique in 2015. Beijing: Ministry of Civil Affairs of the People's Republic of China; 2016. http://www.mca.gov.cn/article/sj/ tjgb/201607/20160715001136.shtml

18. Chen S, Cui Y, Li XW, Ding YP. The unmet needs of activities of daily living and influencing factors among disabled older adults in Nanjing's elderly care agencies. J Nurs Sci. 2017:32(11):70-3.

19. Wang Y, Wang J, Maitland E, Zhao Y, Nicholas S, Lu M. Growing old before growing rich: inequality in health service utilization among the mid-aged and elderly in Gansu and Zhejiang provinces. China BMC Health Services Res. 2012;12:302.

20. Quail JM, Wolfson C, Lippman A. Unmet need for assistance to perform activities of daily living and psychological distress in community-dwelling elderly women. Can J Aging. 2011;30:591-602.

21. Kim J. Factors affecting the unmet long-term care need of elderly in Korea and the United States: effects of children and formal home care on the unmet need. Syracuse: Syracuse University; 1997.
22. LaPlante MP, Kaye HS, Kang T, Harrington C. Unmet need for personal assistance services: estimating the shortfall in hours of help and adverse consequences. J Gerontol Ser B Psychol Sci Soc Sci. 2004;59:98-108.

23. Brimblecombe N, Pickard L, King D, Knapp M. Perception of unmet needs for community social care services in England. A comparison of working carers and the people they care for. Health Soc Care Commun. 2017;25(2):435-46.

24. Kuzuya M, Hirakawa Y, Suzuki Y, Suzuki Y, Iwata M, Enoki H, et al. Association between unmet needs for medication support and all-cause hospitalization in community-dwelling disabled elderly people. J Am Geriatr Soc. 2008;56(5):881-6.

25. DePalma G, Xu HP, Covinsky KE, Stallard E, Thomas J, et al. Hospital readmission among older adults who return home with unmet need for ADL disability. The Gerontologist. 2013;53(3):454-61.

26. Hass Z, DePalma G, Craiq BA, Xu H, Sands LP. Unmet need for help with activities of daily living disabilities and emergency department admissions among older medicare recipients. The Gerontologist. 2017:57(2):206-10.

27. He S, Craig BA, Xu HP, Covinsky KE, Stallard E, Thomas J, et al. Unmet need for ADL assistance is associated with mortality among older adults with mild disability. J Gerontol A Biol Sci Med Sci. 2015;70(9):1128-32.

28. Rhee JC, Done N, Anderson GF. Considering long-term care insurance for middle-income countries: comparing South Korea with Japan and Germany. Health Policy. 2015;119(10):1319-29.

29. U.S. Department of Health and Human Services. Long-term care providers and services users in the United States: data from the national study of long-term care providers, 2013-2014. Vital Health Stat 3. 2016;3:38.

30. Zhu H. Unmet needs in long-term care and their association factors among the oldest old in China. BMC Geriatr. 2015;15(1):46.

31. Mahoney FI, Barthel DW. Functional evaluation: the Barthel index. Maryland State Med J. 1965;14:61-5.

32. Pfeffer RI, Kurosaki TT, Harrah CHJ, Chance JM, Filos S. Measurement of functional activities in older adults in the community. J Gerontol. 1982;37: 323-9.

33. Zarit SH, Reever KE, Back-Peterson J. (1980). Relatives of the impaired elderly: correlates of feelings of burden. The Gerontologist. 1980;20:649-55.

34. Clark NM, Rakowski W. Family caregivers of older adults: improving helping skills. The Gerontologist. 1983;23:637-42.

35. Lee RLT. Caring for family members with stroke:Chinese family caregivers' experiences. Asian J Nurs Stud. 2004:7(1):18-27.

36. Allen SM, Mor $\mathrm{V}$. The prevalence and consequences of unmet need: contrasts between older and younger adults with disability. Med Care. 1997; 35:1132-48.

37. Bradshaw J. A taxonomy of social need. In: McLachlan G, editor. Problems and progress in medical care. London: Oxford University Press; 1972.

38. Liu X. ADL skills and environment adaptations. Beijing: Huaxia publishing house; 2013.

39. Chen W, Fang Y, Mao F, Hao S, Chen J, Yuan M, et al. Assessment of disability among the elderly in Xiamen of China: a representative sample survey of 14,292 older adults. PLoS One. 2015;10(6):e0131014.

40. Wang $\mathrm{H}$, Chen $\mathrm{K}$, Pan $\mathrm{Y}$, Jing F, Liu $\mathrm{H}$. Associations and impact factors between living arrangements and functional disability among older Chinese adults. PLoS One. 2013;8(1):e53879.

41. Hung LC, Liu CC, Kuo HW. Unmet nursing care needs of home-based disabled patients. J Adv Nurs. 2002;40(1):96-104.

42. Qian CG, Xu W, Du J. The qualitative research on caring experiences of family caregivers of disabled elderly in urban areas. Chin J Gen Pract. 2014; 12(1):97-110

43. Desai MM, Lentzner HR, Weeks JD. Unmet need for personal assistance with activities of daily living among older adults. The Gerontologist. 2001;41:82-8.

44. Rice JB, Kasper JD, Pezzin LE. A comparative analysis of Medicaid long-term care policies and their effects on elderly dual enrollees. Health Econ. 2009:18:275-90.

45. Schure MB, Conte KP, Goins RT. Unmet assistance need among older American Indians: the native elder care study. The Gerontologist. 2015;55(6):920-8.

46. Momtaz YA, Hamid TA, Ibrahim R. Unmet needs among disabled elderly Malaysians. Soc Sci Med. 2012;75(5):859-63.

47. Newcomer R, Kang T, Laplante M, Kaye S. Living quarters and unmet need for personal care assistance among adults with disabilities. The journal of gerontology. Series B, psychological science. Soc Sci. 2005;60(4):205-13.

48. Tennstedt S, McKinlay J, Kasten L. Unmet need among disabled elders: a problem in access to community long term care. Soc Sci Med. 1994;38:915-24.

49. Drennan V, Walters K, Lenihan P, Cohen S, Myerson S, lliffe S. Priorities in identifying unmet need in older people attending general practice: a nominal group technique study. Fam Pract. 2007;24:454-60. 